\title{
Time-resolved temperature measurements for inert and reactive particles in explosive atmospheres
}

\author{
F. Beyrau, M.A. Hadjipanayis, R.P. Lindstedt* \\ Department of Mechanical Engineering, Imperial College, \\ Exhibition Road, London SW7 2AZ, UK
}

\begin{abstract}
The current study extends the understanding of the dynamics of the ignition process of fuel-air mixtures caused by laser-irradiated particles via the quantification of the particle heating process. Temperature measurements have been conducted under different irradiance in order to investigate the relationship between the absorption-emission properties of inert and reactive particles using emission spectroscopy. Temporal temperature information has been obtained at different boundary conditions for a range of carbon based powders including carbon blacks and graphites, as well as silicon carbide powders of different sizes. The particle size was found to have a significant impact on the heating process. Specifically, finer particles led to enhanced heating rates due to the reduced mass and thermal capacity, and the rate increase with irradiance for both inert and reactive particles was also quantified. The particle surface temperatures necessary to cause ignition of a surrounding charge were obtained and two different ignition regimes were observed. For non-reactive particles, the surface temperature plays the ma-
\end{abstract}

\footnotetext{
*Corresponding author. Fax: +44 2075893905

Email address: p.lindstedt@imperial.ac.uk (R.P. Lindstedt)
} 
jor role and for silicon carbide particles the ignition temperature was found to be $1200 \pm 200 \mathrm{~K}$. By contrast, results obtained with reactive powders that feature similar times to ignition suggest that the temperature is not the only ignition criterion.

Keywords: Radiation-ignition, Vapour cloud explosions, Carbon black, Emission Spectroscopy

\section{Colloquium: Detonation, Explosions and Supersonic Combustion}

\section{Length of Paper: 6119 (method 2 for LaTex users)}

Main text: 4274; References: 231; Tables: 154; Figures: 1460;

Table 1: $155(\operatorname{method} 2)$

Figure 1: 155 (method 2)

Figure 2: 155 (method 2)

Figure 3: $155(\operatorname{method} 2)$

Figure 4: 155 (method 2)

Figure 5: 155 (method 2)

Figure 6: 155 (method 2)

Figure 7: 155 (method 2)

Figure 8: 155 (method 2)

Figure 9: $220(\operatorname{method} 2)$ 


\section{Introduction}

Loose powders of fine particles can cause ignition of a surrounding fuel-air mixture when heated rapidly by radiation from an infrared laser source [1]. In vapour cloud explosions, fine particles, raised by the expansion of the combustion products, can be exposed to high heat loads due to the forward thermal radiation with infrared characteristics emanating from the hot product cloud. Ignition ahead of the main flame front may be induced with radiation levels similar to those measured in large scale hydrocarbon fires [1]. Likewise, fibrous targets that exhibit high absorption in the far-infrared (FIR), while their volumetric heat capacity is maintained at similar levels to that of the adjacent fuel-air mixture, can also cause ignition $[2,3,4]$.

Radiative ignition is also of potential importance for the assessment of ignition hazards arising from the use of optical fibres in flammable atmospheres. Light emanating from faulty fibre optic systems can heat particle(s) causing an accidental ignition. Hills et al. [5] and Zhang et al. [6] showed that for ignition of hydrogen-air mixtures by a single coal particle held at the fibre tip, the ignition process was controlled by the incident laser power, while Adler et al. [7] showed that ignition by fibrous mats irradiated using large beam cross-sections is determined by the incident power flux. Carleton and Weinberg [8], reported that this relates to the minimum ignition energy of the mixture which varies linearly with the time and area.

Whilst the necessary incident power or flux required to cause ignition are relatively well documented, little is known about the particle surface temperatures and, in particular, their temporal evolution. Stamatov et al. [9] suggest that temperatures of at least $950 \mathrm{~K}$ are necessary for ignition of a 
stoichiometric methane-air mixture by radiatively heated inert particles with a size of $320-480 \mu \mathrm{m}$, while calculations carried out by Hills et al. [5], for ignition of a lean hydrogen-air mixture by an irradiated coal particle, suggest a particle surface temperature of $800 \mathrm{~K}$. Adler et al. [7] suggest temperatures of $928 \mathrm{~K}$ and $950 \mathrm{~K}$ for ignition of stoichiometric propane- and methane-air mixtures by a silicon carbide coated Kaowool mat (inert insulation wool) irradiated by $1064 \mathrm{~nm}$ light. Similarly, for spheres made of plain Kaowool fibres irradiated by FIR light, the corresponding temperatures were $922 \mathrm{~K}$ and $1022 \mathrm{~K}$ for the same mixtures.

Beyrau et al. [1] examined a unique system featuring sub-micron particles irradiated over comparatively large areas in ignitable butane-air mixtures. The experimental study featured fine powders with very different characteristics (type, size, morphology, etc.) and the ignition times scales were found to decrease with increasing irradiance. A commercially available carbon black powder (acetylene black) coated on a glass substrate was found to give rise to short ignition time scales $(\simeq 100 \mathrm{~ms})$ in a stoichiometric butane-air mixture using an irradiance $<600 \mathrm{~kW} / \mathrm{m}^{2}$. Due to the high spectral absorptivity in the infrared, the enhanced heat transfer to adjacent gas due to the nanostructure particle surface and, possibly, the favourable chemical reactivity, carbon black powders produced very short ignition times. However, there is little further knowledge on the heating behaviour of these powders and, more importantly on the particle surface temperatures necessary to cause ignition of an adjacent flammable mixture.

Apart from the fundamental interest to combustion science, it is expected that the simultaneous characterisation of ignition events in terms of surface 
temperature in addition to the established times to ignition [1] will enable a multi-parameter (e.g., temperature and time to ignition) validation of future calculation methods aimed at representing this novel ignition mechanism and thereby support the development of improved tools for the quantitative assessment of explosion hazards. The objective of the current study is hence to extend the understanding of the dynamics of the ignition process under idealised conditions (e.g., no attenuation from the particles and maximum absorption) that can be considered a worst case scenario for a practical event. The relationship between absorption-emission properties of different powders is investigated further by the determination of particle temperatures under different irradiance using emission spectroscopy (ES) [10]. The materials used (e.g., carbon black, graphite, silicon carbide) feature relatively well defined emissivities and, hence, particle thermometry is used to obtain useful information on the ignition mechanism. Finally, results from the study by Beyrau et al. [1] suggest that the chemical reactivity of carbon black powders may influence the ignition process; this hypothesis is examined on the basis of determined particle temperatures.

The present study extends previous efforts by systematic investigations into the heating behaviour of different powders at different boundary conditions. (i) Steady state temperatures are established as a function of the incident irradiance. (ii) Temporal temperature information is obtained for both inert and reactive particles. (iii) The influence of the powder particle size on the corresponding heating behaviour is explored under constant irradiance and (iv) the surface temperatures necessary to cause ignition are determined for both reactive and inert particles. 


\section{Experimental method}

A stainless steel flame tube of $90 \times 60 \mathrm{~mm}$ rectangular cross-section and $240 \mathrm{~mm}$ length was used [1]. The chamber was equipped with a fused silica window $(115 \times 60 \mathrm{~mm})$ which allowed the simultaneous illumination of the selected targets and the use of optical diagnostics techniques. The desired equivalence ratio $(\phi)$ was obtained using the method of partial pressures via a pressure transducer (KIMO MP $105 \mathrm{E}$ ) with a reading accuracy of $0.5 \%$. For a stoichiometric butane-air mixture the resulting overall accuracy was $\phi=1.0 \pm 0.02$. The reactants were fed into the tube via the dedicated lines shown in Fig. 1. Mixture homogeneity was achieved after circulating the reactants for 70 flow-through times in a closed loop. The open end of the tube was sealed using a thin aluminium foil that ruptured due to the pressure rise following ignition [1].

Candidate particulates were placed at the centre of the flame tube and illuminated by a near-infrared (NIR) continuous wave laser diode $(808 \pm 2 \mathrm{~nm}$, $50 \mathrm{~W}$ ). Full lasing could be achieved within $2 \mathrm{~ms}$ given a pre-determined target power, thus enabling a sufficiently precise definition of the illumination time. The laser power was measured for each experiment via an on-board monitor diode. The spatial distribution of laser power was determined using a CCD camera. The beam size was considered as $68 \%(1 / \mathrm{e})$ of the Gaussian laser profile; a maximum irradiance of $1.6 \mathrm{MW} / \mathrm{m}^{2}$ could be applied over approximately $32 \mathrm{~mm}^{2}$. The conditions used in the current study follow Beyrau et al. [1] unless otherwise stated. Ignition times $\left(\tau_{i g n}\right)$ were obtained from images recorded by a CCD camera (AVT PIKE F-032 COLOR) at a rate of $208 \mathrm{fps}$. The onset of ignition was regarded as the appearance of 
visible flame in the recorded frames, while the ignition time was defined as the interval from illumination to ignition corresponding to an uncertainty of $\pm 5 \mathrm{~ms}$. The reported times include the particle and gas heating times and are, hence, different from conventional induction times. Once the investigated target was positioned, the tube was sealed, the mixture produced and the powder irradiated.

Time-resolved spectroscopic temperature measurements were performed using an Ocean Optics NIRQuest 512 spectrometer (900 - $1700 \mathrm{~nm}$ ) fitted with a notch filter $(808 \mathrm{~nm})$ to suppress the scattered laser light. The spectrometer was triggered from the laser and collected the emitted radiation from the illuminated powder via an optical fibre/collimator assembly at a rate of $200 \mathrm{fps}$ using an integration time of $1 \mathrm{~ms}$. The spectral response of the spectrometer was corrected using a calibrated light source (Ocean Optics Cool Red Infrared Light Source) with a bulb colour temperature of $1500 \mathrm{~K}$. The produced correction curves accounted also for the chromatical errors from the collimator, fibre and the notch filter. Particle temperatures were obtained using ES, a non-intrusive optical diagnostic technique which has been successfully used for measuring soot temperatures in flames [10]. The technique is based on the analysis of the spectrally resolved emitted radiation. Temperatures were obtained by fitting of the theoretical spectra according to Planck's law of radiation to the experimentally determined one over a spectral range of $900-1650 \mathrm{~nm}$. More details on the method can be found elsewhere [11, 12]. For the current investigation the emission coefficient $(\varepsilon)$ for all powders was assumed to be unity as discussed in Section 3.1.

The temperature within the irradiated spot might not be uniform due 
to the Gaussian radial energy distribution of the heating laser beam. The spectrometer collected light from an area approximately half of the irradiated spot; this was achieved by overlapping the laser spot and the field of view of the spectrometer using a low power target diode laser. The temperature is expected to be approximately uniform in this reduced region and, hence, the Gaussian beam profile is not expected to cause appreciable errors. The investigated powders featured a non-uniform particle size distribution and, thus, particles or the primary carbon black particles within the interrogation region may feature non-identical heating rates due to differences in their thermal inertia. The sampling technique used is non-linear and highly sensitive to high temperatures since the collected signal follows the Stefan-Boltzmann law of radiation and thus proportional to the fourth power of temperature. Therefore, irrespective of any spatial temperature non-uniformities, a nonlinearly averaged peak temperature is determined within the sampled area rather than a spatially averaged equivalent. The average, maximum and minimum values were obtained from three measurements at each condition. An illustrative figure is provided in the Supplemental material and shows the spectra obtained from three tests. The temperature sensitivity is such that good accuracy is maintained over the full range of current conditions.

The influence on the heating behaviour was examined for a range of powders of different chemical reactivity, spectral absorptivity and surface area to volume ratio as shown in Table 1 . The materials include a collection of commercially available carbon blacks, a natural and a synthetic graphite and chemically inert silicon carbides. Carbon blacks used in this study included Alfa Aesar Acetylene Black, Evonik Printex 35 and 80, and Evonik 
Colour Black FW1. Both graphite powders were sifted through a $45 \mu \mathrm{m}$ sieve. Silicon carbide powders, featuring a median particle size $\left(\mathrm{d}_{50}\right)$ from 0.6 to $370 \mu \mathrm{m}$, were considered to explore the influence of the particle size. Particle size distributions for selected silicon carbide powders can be found in the Supplemental material. The carbon based powders appear black at optical wavelengths and exhibit high absorption at the incident laser light of $808 \mathrm{~nm}$. Silicon carbides appear grey and experimental data [7] suggest lower absorptivity than soot. Our previous investigation [1] showed that the properties of powder coatings have a much stronger impact on ignition than the properties of the substrate, therefore in the current study only microscope coverslips and slides were used. A thin layer (a few hundred $\mu \mathrm{m}$ thick), sufficient to appear optically dense (i.e., a transparent glass substrate became opaque), was applied. The particle type, incident irradiance, particle size and adjacent atmosphere were varied individually and the effect on the heating behaviour of the powder was recorded.

\section{Results and discussion}

\subsection{The influence of powder absorptivity on the equilibrium temperature}

Initial experiments were performed to examine the accuracy of the applied optical diagnostic technique. A validation test was carried out by comparing the steady state temperature obtained with the spectroscopic technique with temperatures measured simultaneously using a type $\mathrm{R}$ thermocouple of $0.125 \mathrm{~mm}$ diameter. For this experiment, silicon carbide $\left(\mathrm{d}_{50}=0.6 \mu \mathrm{m}\right)$ and acetylene black powder coated on microscope slides were used and the thermocouple tip was buried in the investigated powder at the centre of the 
irradiated area where peak temperatures occur. The method was used to minimise the radiation errors in the thermocouple readings. Results are depicted in Fig. 2. The excellent agreement shows that ES is suitable for measuring temperatures $(800-1600 \mathrm{~K})$ of current interest. Apart from being non-intrusive, the optical diagnostic technique offers superior time resolution (200 fps) compared to conventional thermocouple measurements. Also, the assumption of a unity emission coefficient for both materials appears to be a good approximation. Visually black and grey materials are usually modelled with unit emissivity and deviations are expected to be modest.

Higher irradiance yields higher equilibrium temperatures as well as rate of temperature rise; both directly relate to the time to ignition of an adjacent charge. Equilibrium temperatures reached in air for a range of irradiance for acetylene black and silicon carbide $\left(\mathrm{d}_{50}=19 \mu \mathrm{m}\right)$ are shown in Fig. 3, along with data from Adler et al. [7] obtained with coated fibrous targets heated by light of a comparable wavelength $(1064 \mathrm{~nm})$. The temperature dependence on irradiance shows a similar trend for both materials. Also, it is apparent that the interplay between absorption-emission properties of individual powders leads to differences between the equilibrium temperatures achieved. Temperatures for silicon carbide and acetylene black vary from 1130 to $1337 \mathrm{~K}$ at $310 \mathrm{~kW} / \mathrm{m}^{2}$ and from 1752 to $1840 \mathrm{~K}$ at $1.6 \mathrm{MW} / \mathrm{m}^{2}$, while the data from Adler et al. [7] range from 842 to $1202 \mathrm{~K}$ at $250 \mathrm{~kW} / \mathrm{m}^{2}$ for silicon carbide and soot respectively. Interestingly, acetylene black temperatures obtained with an irradiance of $310 \mathrm{~kW} / \mathrm{m}^{2}$ are above the approximate onset of high temperature ignition $(1200 \mathrm{~K})$ promoted by chain branching [13]. The silicon carbide particles can reach similar temperatures with an 
irradiance of $625 \mathrm{~kW} / \mathrm{m}^{2}$, while the soot coated mats [7] do so with an irradiance of $375 \mathrm{~kW} / \mathrm{m}^{2}$. It should be also stated that with the acetylene black and silicon carbide particles ignition of a stoichiometric butane-air mixture was readily observed with these irradiance levels [1], albeit the ignition times were of the order of $1 \mathrm{~s}$.

\subsection{The influence of irradiance and target particle properties on the heating} behaviour of the powder

When the irradiance increases, it can be expected that the rate of temperature rise will also increase. The effect is quantified in Fig. 4, where results for acetylene black particles on a coverslip in air are presented along with the corresponding ignition times in a stoichiometric-butane air mixture (obtained from Beyrau et al. [1]). The time resolution of the optical diagnostic technique used enables the accurate characterisation of the initial heating stages. As mentioned earlier, the measured ignition time scales in a surrounding charge decreased with increasing irradiance, this directly relates to the increased heating rates. This also applies to non-reactive particles, the influence of irradiance on the heating behaviour of silicon carbide particles can be seen in Fig. 5. Compared to the reactive acetylene black particles, silicon carbide exhibits lower heating rates at the same irradiance. This may be an effect of the lower spectral absorptivity as well as the particle surface structure. Previous Scanning Electron Microscope (SEM) images have shown that the morphological features of acetylene black are characterised by primary particles of $35 \mathrm{~nm}$, clustered into structures with interstitial spaces [1]. This nanostructure particle surface may give rise to favourable heating characteristics. Also the reactive nature of acetylene black may assist the particle 
heating process. Nevertheless, the use of the non-combustible silicon carbide enables the characterisation of the direct thermal ignition process. Obtaining the precise chemical composition of reactive powders may not be trivial. Hence, it is expected that knowledge of the temporal temperature evolution of non-reactive particles will allow the validation of simplified models, used for simulating this ignition process, that do not include surface reactions.

The temperature evolution of silicon carbide in air under constant irradiance was measured as a function of the powder median particle size, as is shown for different silicon carbide powders in Fig. 6. The inert silicon carbide powders were specifically chosen for this investigation in order to make sure that results were a function of the particle size only. It can be seen that the rate of temperature rise increases with decreasing particle size. Measurements were also carried out for a coarse grain powder $\left(\mathrm{d}_{50}=370 \mu \mathrm{m}\right)$. However, results are not presented since temperatures higher than $1000 \mathrm{~K}$ were only observed after $600 \mathrm{~ms}$. It has been previously shown that fine grain powders featured more than an order of magnitude shorter ignition times than coarse particles in a stoichiometric butane-air mixture [1], this directly relates to the corresponding heating behaviour. Finer particles feature higher surface area to volume ratio as well as lower mass and thermal capacity. Hence, the high temperatures necessary for the ignition of the surrounding charge can be reached more quickly. A temperature of $1040 \mathrm{~K}$ is reached after $37 \mathrm{~ms}$ for a $0.6 \mu \mathrm{m}$ powder, while the $58 \mu \mathrm{m}$ powder reaches the same temperature after $152 \mathrm{~ms}$. Although not measured here, the equilibrium temperature reached in air is expected to be similar irrespective of the particle size as it is expected that the powders feature similar absorptivity. 
Fine particles enhance also the heat conduction to the surrounding gas phase due to the larger specific surface area, which assists the reduction of ignition times.

\subsection{Particle surface temperatures upon ignition of explosive mixtures}

Time-resolved temperature histories for acetylene black powders in air and in stoichiometric butane-air mixtures are shown in Fig. 7. The particle heating behaviour appears to be similar in a non-flammable and an explosive atmosphere. Accordingly, if it is assumed that the heating behaviour in air and in a fuel-air mixture does not change significantly, then the particle surface temperature required for ignition may be estimated. This is achieved by examining the powder temperature at the average time of ignition. This is a reasonable assumption since most the explosive mixtures of practical interest contain relatively small amounts of fuel and, hence, their thermal conductivity is expected to be very similar to air.

The estimated "ignition temperatures" can be seen in Fig. 8. The horizontal error bars correspond to the maximum and minimum temperatures measured during the equivalent ignition time. Two different ignition regimes can be observed, if the particle is non-reactive the ignition temperature is $1200 \pm 200 \mathrm{~K}$. For particle sizes from around 37 to $370 \mu \mathrm{m}$, which feature an order of magnitude difference in ignition times [1], the ignition temperatures are in a comparatively narrow band from 1290 to $1327 \mathrm{~K}$. The value drops to around $1180 \mathrm{~K}$ for particles in the range 9 to $19 \mu \mathrm{m}$. The variation of the ignition temperature as a function of powder median particle size for different silicon carbide powders can be found in the Supplemental material. For comparison, measurements from Adler et al. [7] suggest tem- 
peratures of $928 \mathrm{~K}$ for propane and $950 \mathrm{~K}$ for methane for ignition by silicon carbide coated on a (Kaowool) fibrous substrate, irradiated by $1064 \mathrm{~nm}$ light in mixtures of unit stoichiometry. Moreover, Laurendeau [14] reported that for thermal ignition of methane-air mixtures by a hot surface, temperatures above $1273 \mathrm{~K}$ are required. Findings from the current study suggest that if the particles are non-reactive the surface temperature plays the major role in the ignition of the surrounding charge. This was indeed expected since the phenomenon of ignition by radiatively heated inert particles is characterised by direct thermal ignition.

For reactive powders, the particle surface temperature does not appear to be the sole ignition criterion. The ignition temperature of acetylene black, $\tau_{\text {ign, Ace }}=20 \mathrm{~ms}$, is $1270 \pm 60 \mathrm{~K}$ while Printex $80, \tau_{i g n, \text { P } 80}=85 \mathrm{~ms}$, featured an ignition temperature of $1700 \pm 50 \mathrm{~K}$, at least $320 \mathrm{~K}$ higher. These two powders exhibited ignition times below $100 \mathrm{~ms}$ in a stoichiometric butane-air mixture. Ignition temperatures for Printex 35 were $1588 \pm 70 \mathrm{~K}$, $\tau_{i g n, \text { P35 }}=51 \mathrm{~ms}$; for Colour FW1 $1652 \pm 20 \mathrm{~K}, \tau_{i g n, \text { FW1 }}=38 \mathrm{~ms}$; for natural graphite $1385 \pm 75 \mathrm{~K}, \tau_{i g n, \text { GN }}=127 \mathrm{~ms}$; and for synthetic graphite $1355 \pm 145 \mathrm{~K}, \tau_{i g n, \mathrm{GS}}=63 \mathrm{~ms}$. SEM images of the carbon black powders used can be found in Fig. 9 and as discussed by Beyrau et al. [1]. The carbon black powders examined have distinct morphological features. Acetylene black is characterised by relatively large primary particles (35 nm) and smaller structures with interstitial spaces, while Printex 80 by both smaller primary particles size $(16 \mathrm{~nm})$ and structures without voids. The morphological characteristics influence the reactivity of powders. The differences may relate to local mixture enrichment effects due to evaporating 
carbon near the particle surface or the chemical reactivity of individual powders. The measured times to ignition reported by Beyrau et al. [1] suggest that the powder reactivity may influence this ignition mechanism, the large variation in the ignition temperatures of reactive particles observed in the current study confirms this argument. It has been reported that soot particles undergo structural modification upon exposure to continuous (e.g., Hu et al. [15], $55 \mathrm{MW} / \mathrm{m}^{2}$ ) or pulsed laser irradiation (e.g., Vander Wal et al. [16], $\left.5 \times 10^{5} \mathrm{MW} / \mathrm{m}^{2}\right)$. The maximum laser irradiance used in the current study is of the order of $1 \mathrm{MW} / \mathrm{m}^{2}$ and, hence, it is not expected that such structural modification or laser ablation phenomena will substantially influence the ignition process. Previous SEM analysis [1] has indicated that the morphological features of acetylene black closely resembles car exhaust related particles. Results presented in the current study show that this type of particles provides the most favourable ignition characteristics with low ignition temperatures, in addition to the shortest ignition times.

\section{Conclusions}

Emission spectroscopy, a method for soot particle surface temperature measurements in flames [10], has been used to determine time-resolved temperatures of irradiated powders under radiation levels relevant to radiation induced ignition in flammable atmospheres. This allowed the comprehensive quantification of particle heating process for both inert and reactive particles. The dependence of equilibrium temperature on irradiance attained in air by silicon carbide and acetylene black showed a similar trend with coated fibrous targets [7]. Furthermore, the rate of temperature rise in- 
creases with irradiance for both particle types which explains the decrease in ignition times of a surrounding explosive atmosphere. Finer particles led to enhanced heating rates due to the reduced mass and thermal capacity. Particle surface temperatures necessary to cause ignition of a surrounding charge were estimated from temperature histories obtained in air. Two different ignition regimes were observed, if the particles are non-reactive the surface temperature plays the major role in the ignition of the surrounding explosive mixture. For silicon carbide particles, ignition temperatures were $1200 \pm 200 \mathrm{~K}$ for powders with different particle sizes. In contrast, for reactive powders, the temperature appeared to be not the only ignition criterion indicated by the different values measured with powders that feature similar times to ignition. Furthermore, previous SEM analysis [1] has indicated that the morphological features of acetylene black closely resembles car exhaust related particles. The current study suggests that this type of particles show the most favourable ignition characteristics with low ignition temperatures, in addition to the shortest ignition times. In summary, the present work has enabled the simultaneous characterisation of ignition events in terms of surface temperature in addition to the established ignition time scales. It is expected that data sets produced will enable a multi-parameter (e.g., temperature and time to ignition) validation of calculation methods aimed at representing this novel ignition mechanism and thereby support the development of improved tools for the quantitative assessment of explosion hazards. 


\section{Acknowledgements}

The authors are indebted to the Health \& Safety Laboratory of the Health and Safety Executive for providing financial support for the current study.

The authors wish also to acknowledge Graham Atkinson, Laurence Cusco, Hans Michels and Bob Simpson for encouraging this work.

\section{References}

[1] F. Beyrau, M.A. Hadjipanayis, R.P. Lindstedt, Proc. Combust. Inst. 34 (2) (2013) 2065-2072.

[2] S.R. Moore, F.J. Weinberg, Nature 290 (1981) 39-40.

[3] S.R. Moore, F.J. Weinberg, Proc. R. Soc. Lond. A 385 (1983) 373-387.

[4] S.R. Moore, F.J. Weinberg, Proc. R. Soc. Lond. A 409 (1987) 1-20.

[5] P.C. Hills, D.K. Zhang, P.J. Samson, T.F. Wall, Combust. Flame 91 (3-4) (1992) 399-412.

[6] D.K. Zhang, P.C. Hills, C. Zheng, T.F. Wall, P. Samson, Proc. Combust. Inst. 24 (1) (1992) 1761-1767.

[7] J. Adler, F.B. Carleton, F.J. Weinberg, Proc. R. Soc. Lond. A 440 (1993) 443-460.

[8] F.B. Carleton, F.J. Weinberg, Proc. R. Soc. Lond. A 447 (1994) 513-526.

[9] V.A. Stamatov, K.D. King, D.K. Zhang, Fuel 84 (16) (2005) 2086-2092. 
365 [10] M.C. Weikl, T. Seeger, M. Wendler, R. Sommer, F. Beyrau, A. Leipertz, $366 \quad$ Proc. Combust. Inst. 32 (1) (2009) 745-752.

367 [11] G.B. Hunter, C.D. Allemand, T.W. Eagar, Opt. Eng. 24 (6) (1985) 368241081.

369 [12] S. Schraml, S. Dankers, K. Bader, S. Will, A. Leipertz, Combust. Flame $370 \quad 120(4)(2000) 439-450$.

371 [13] J. Warnatz, U. Maas, R.W. Dibble, Combustion, Springer, Germany, $372 \quad 2001$, p. 230

373 [14] N.M. Laurendeau, Combust. Flame 46 (1982) 29-49.

374 [15] L. Hu, S. Wang, B. Zhang, Y. Zeng, Carbon 44 (9) (2006) 1725-1729.

375 [16] R.L. Vander Wal, M.Y. Choi, K.-O. Lee, Combust. Flame 102 (1-2) $376 \quad$ (1995) 20-204. 


\section{${ }_{377}$ Tables}

Table 1: Powder data

\begin{tabular}{|c|c|c|c|c|}
\hline Powder & Colour & $\begin{array}{l}\text { Chemical } \\
\text { Formula }\end{array}$ & $\begin{array}{l}\text { Particle } \\
\text { Size } \\
(\mu \mathrm{m})\end{array}$ & $\begin{array}{l}\text { Primary } \\
\text { Particle } \\
\text { Size } \\
(\mathrm{nm})\end{array}$ \\
\hline $\begin{array}{l}\text { Acetylene } \\
\text { Black }\end{array}$ & Black & $\mathrm{C}$ & - & 35 \\
\hline Printex 35 & Black & $\mathrm{C}$ & - & 31 \\
\hline Printex 80 & Black & $\mathrm{C}$ & - & 16 \\
\hline $\begin{array}{l}\text { Colour } \\
\text { FW1 }\end{array}$ & Black & $\mathrm{C}$ & - & - \\
\hline $\begin{array}{l}\text { Natural } \\
\text { Graphite }\end{array}$ & Black & $\mathrm{C}$ & $<45$ & - \\
\hline $\begin{array}{l}\text { Synthetic } \\
\text { Graphite }\end{array}$ & Black & $\mathrm{C}$ & $<45$ & - \\
\hline $\begin{array}{l}\text { Silicon } \\
\text { Carbide }\end{array}$ & Grey & $\mathrm{SiC}$ & $\begin{array}{l}d_{50}=0.6 \\
9.3,19 \\
37,58\end{array}$ & - \\
\hline
\end{tabular}




\section{Figures}

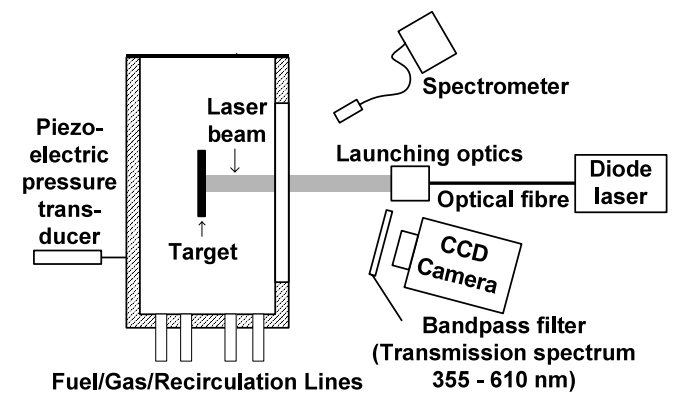

Fig. 1: Schematic of the experimental facility used for the particle thermometry.

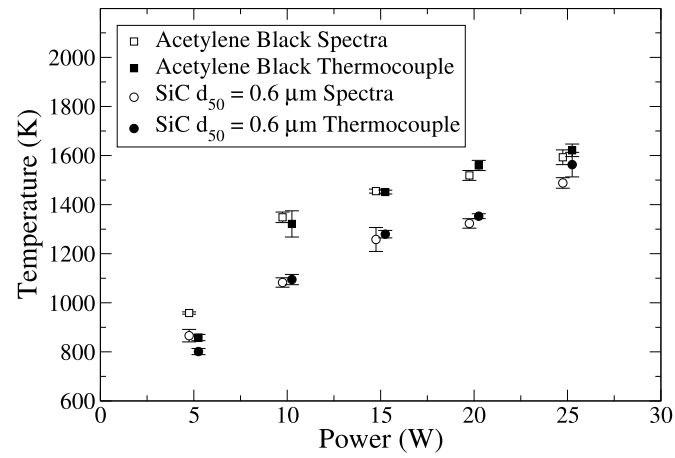

Fig. 2: Comparison of equilibrium temperature measurements of carbon black and silicon carbide on a microscope slide in air. 


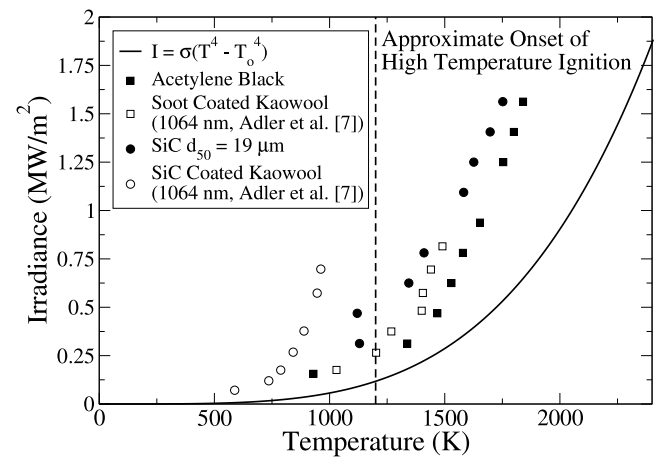

Fig. 3: Irradiance against equilibrium temperature attained in air by silicon carbide $\left(\mathrm{d}_{50}=19 \mu \mathrm{m}\right)$ and acetylene black on microscope coverslip. The vertical dashed line indicates the approximate onset of high temperature ignition $(1200 \mathrm{~K})$ promoted by chain branching [13].

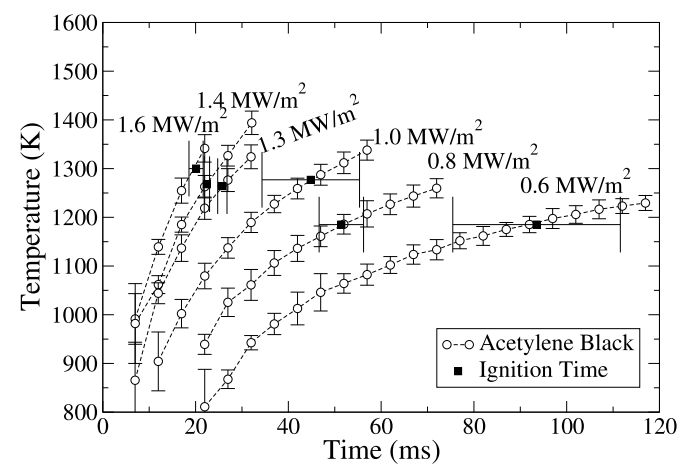

Fig. 4: Temperature histories of acetylene black on a microscope coverslip in air for different irradiance. Ignition times correspond to the average obtained in a stoichiometric butane-air mixture using the same irradiance [1]. 


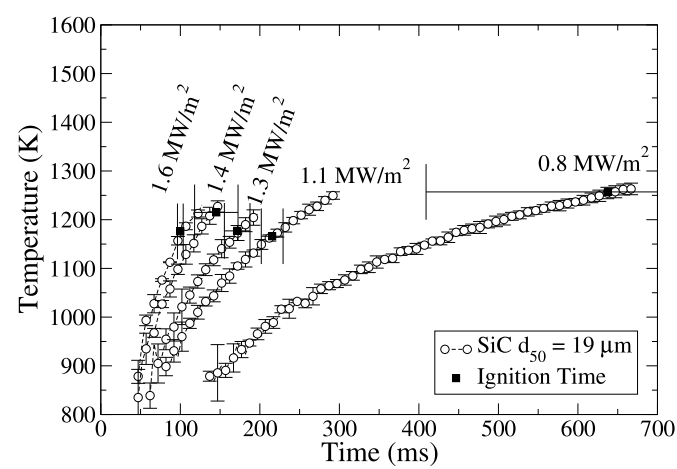

Fig. 5: Temperature histories of silicon carbide $\left(\mathrm{d}_{50}=19 \mu \mathrm{m}\right)$ on a microscope coverslip in air for different irradiance. Ignition times correspond to the average obtained in a stoichiometric butane-air mixture using the same irradiance [1].

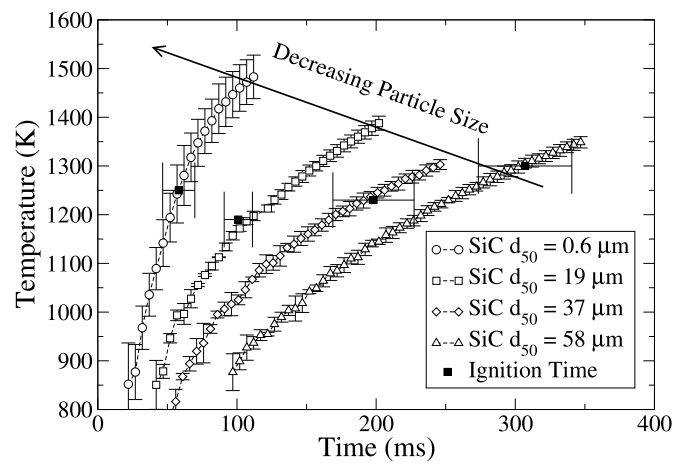

Fig. 6: Temperature histories of silicon carbide on a microscope coverslip in air for different particle sizes, irradiance $=1.6 \mathrm{MW} / \mathrm{m}^{2}$. Ignition times correspond to the average obtained in a stoichiometric butane-air mixture using the same irradiance [1]. 


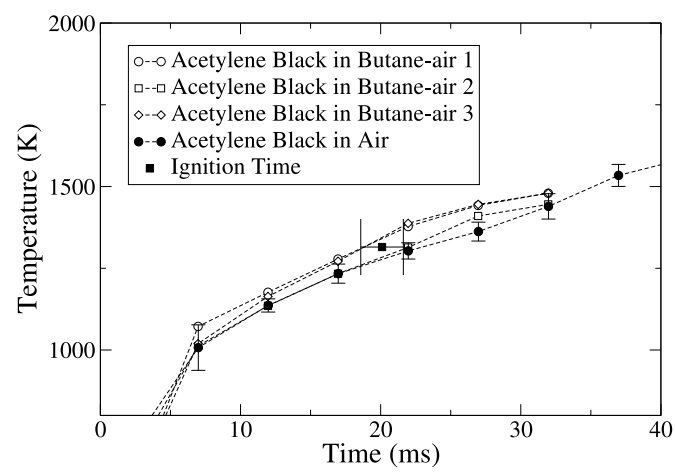

Fig. 7: Temperature histories of acetylene black on a microscope coverslip in air and a stoichiometric butane-air mixture, irradiance $=1.6 \mathrm{MW} / \mathrm{m}^{2}$. Ignition times correspond to the average obtained in a stoichiometric butane-air mixture using the same irradiance [1].

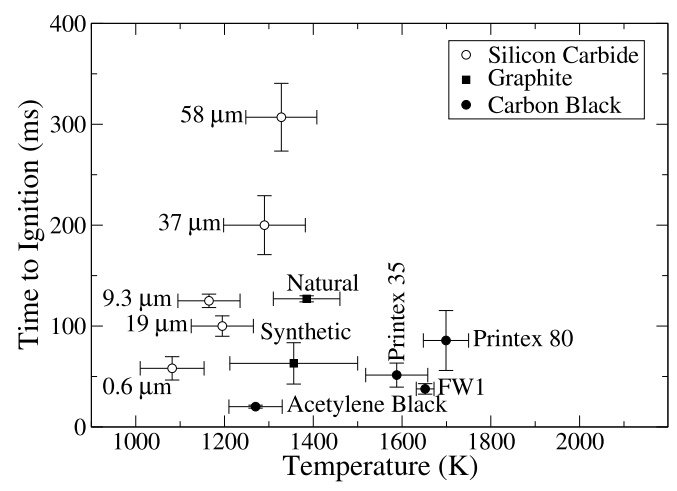

Fig. 8: "Ignition temperatures" for a stoichiometric butane-air mixture deducted from temperature histories in air and the corresponding ignition times [1], irradiance $=1.6 \mathrm{MW} / \mathrm{m}^{2}$. 


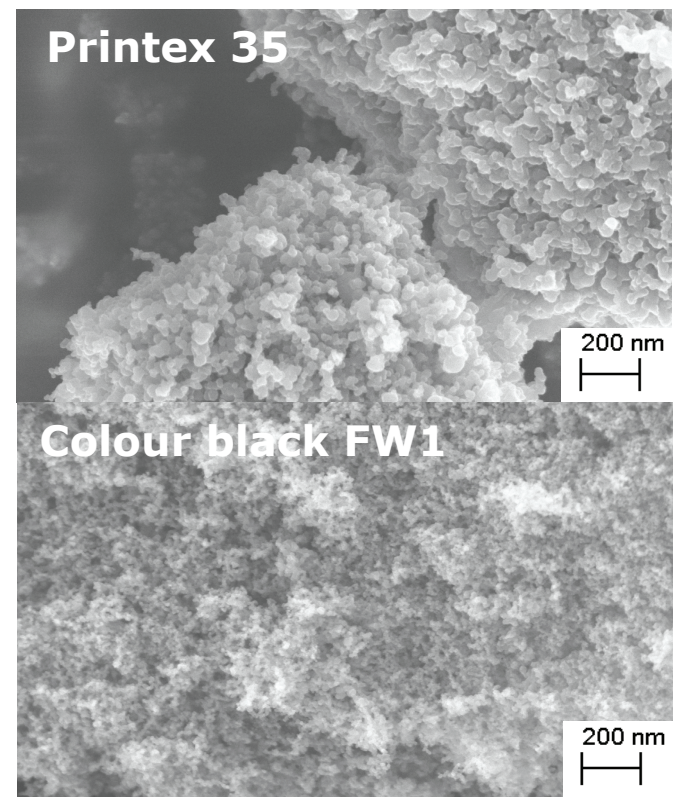

Fig. 9: SEM images of the selected carbon black powders. Ignition times in stoichiometric butane/air mixture, irradiance $=1.6 \mathrm{MW} / \mathrm{m}^{2}:$ Printex $35\left(\tau_{i g n}=52 \mathrm{~ms}\right)$; Colour FW1 $\left(\tau_{\text {ign }}=38 \mathrm{~ms}\right)$. 


\section{List of Tables}

1 Powder data . . . . . . . . . . . . . . . . . 19

\section{List of Figures}

1 Schematic of the experimental facility used for the particle thermometry. .................... 20

2 Comparison of equilibrium temperature measurements of carbon black and silicon carbide on a microscope slide in air. . . . 20

3 Irradiance against equilibrium temperature attained in air by silicon carbide $\left(\mathrm{d}_{50}=19 \mu \mathrm{m}\right)$ and acetylene black on microscope coverslip. The vertical dashed line indicates the approximate onset of high temperature ignition (1200 K) promoted by chain branching [13]. . . . . . . . . . . . . . . . . 21

4 Temperature histories of acetylene black on a microscope coverslip in air for different irradiance. Ignition times correspond to the average obtained in a stoichiometric butane-air mixture using the same irradiance $[1]$. . . . . . . . . . . . . . . . . 21

5 Temperature histories of silicon carbide $\left(\mathrm{d}_{50}=19 \mu \mathrm{m}\right)$ on a microscope coverslip in air for different irradiance. Ignition times correspond to the average obtained in a stoichiometric butane-air mixture using the same irradiance [1] . . . . . . . . 22

6 Temperature histories of silicon carbide on a microscope coverslip in air for different particle sizes, irradiance $=1.6 \mathrm{MW} / \mathrm{m}^{2}$. Ignition times correspond to the average obtained in a stoichiometric butane-air mixture using the same irradiance [1] . . . . 22 
7 Temperature histories of acetylene black on a microscope coverslip in air and a stoichiometric butane-air mixture, irradiance $=1.6 \mathrm{MW} / \mathrm{m}^{2}$. Ignition times correspond to the average obtained in a stoichiometric butane-air mixture using the same irradiance $[1] . \ldots \ldots \ldots$

8 "Ignition temperatures" for a stoichiometric butane-air mixture deducted from temperature histories in air and the corresponding ignition times $[1]$, irradiance $=1.6 \mathrm{MW} / \mathrm{m}^{2} \ldots \ldots 23$

9 SEM images of the selected carbon black powders. Ignition times in stoichiometric butane/air mixture, irradiance $=1.6$ $\mathrm{MW} / \mathrm{m}^{2}$ : Printex 35 ( $\left.\tau_{i g n}=52 \mathrm{~ms}\right)$; Colour FW1 ( $\left.\tau_{i g n}=38 \mathrm{~ms}\right) .24$ 